\title{
REELABORAÇÃO DE GÊNEROS UMA PRÁTICA LINGÜÍSTICA/DISCURSIVA
}

\author{
Rita de Cássia Souto Maior Siqueira Lima ${ }^{1}$
}

\begin{abstract}
RESUMO
Neste artigo proponho discutir a importância dos gêneros discursivos no trabalho de sala de aula para a configuração de uma prática lingüística voltada para a prática social. Inicio com um breve esboço teórico da concepção de gênero, dividindo as diferentes visões a respeito desse tema em dois grandes blocos. Em seguida desenvolvo um pouco de cada um desses grandes campos, definindo língua/linguagem e o que se configuraria como gênero em cada uma das visões nelas inseridas metodologicamente. Por fim proponho uma atividade pedagógica de transformações genéricas, resultantes de um deslocamento também ideológico-crítico.
\end{abstract}

PALAVRAS-CHAVE: gênero, ensino e aprendizagem, linguagem, ideologia

\section{INTRODUÇÃO}

Os estudos teóricos foram sistematizando a idéia de gêneros de acordo com a época histórica em que se desenvolveram e das concepções de homem e mundo que os subsidiaram. Os posicionamentos filosóficos-teóricos a respeito do que o homem pode operar de acordo com seu intuito discursivo fizeram revelar, ao longo dos tempos, suposições a respeito de sua escrita e, principalmente, de suas formas de escrever. Inicialmente, valendo-me do dispositivo histórico, apresentei, neste estudo, um levantamento de algumas das diferentes concepções de gênero que se pode apontar. Por fim, após associá-las a determinados paradigmas teóricos, defendo a importância de se considerar que, hoje, há uma necessidade premente em se fazer atividades em sala de aula voltadas para o reconhecimento da importância da reelaboração dos "tipos" de escrita. Parto, para essa conclusão, das idéias de Schneuwly e Dolz (2004) e do conceito de reelaboração de Bakhtin (2003).

\section{ESBOÇO TEÓRICO DO TERMO “GÊNERO”}

A "palavra” tinha uma importância singular na Grécia Antiga. Segundo Faria (1994, p. 16), para entender a dimensão dessa importância, faz-se necessário entender o contexto histórico-político do momento em questão. A democracia não era representativa como hoje, e

\footnotetext{
1 Mestranda no Programa de Pós-graduação em Letras e Linguiística da Universidade Federal de Alagoas. Bolsista Cnpq. Trabalho em Lingüística Aplicada.
} 
todos tinham o direito e até o dever de participar das assembléias promovidas em praça. Logo, "falar bem" era uma arma política de importância fundamental para essa fase histórica-social.

A partir desse esclarecimento, fica fácil perceber o caráter político-pedagógico das obras classificatórias dos gêneros da época. Os propósitos justificavam o esforço em discriminar e, mais ainda, em prescrever as formas de dizer, dentro de modelos a serem seguidos pelos cidadãos que tinham participação ativa, como já foi dito, nos acontecimentos públicos sociais.

Em suas obras Arte Retórica e Arte Poética, Aristóteles trata dos gêneros de forma a classificá-los conforme um grupo de características. Na Arte retórica, o autor classifica os gêneros de acordo com: a) as categorias dos ouvintes do discurso; b) a funcionalidade desse discurso e; c) a sua temporalidade. Esses elementos são apresentados em inter-relações como veremos adiante.

Para esse filósofo o discurso se compõe de três elementos: a pessoa que fala, o tema que se fala e a pessoa para quem se fala. De acordo com o posicionamento desse último, ou seja, da pessoa para quem se fala, que ele chama ouvinte, é que os gêneros são classificados.

O ouvinte pode ser, ainda, espectador ou juiz e, se juiz, falará sobre o passado ou sobre o futuro. Caso fale sobre o passado é o juiz propriamente dito, já se esse ouvinte tiver que decidir acerca do futuro, ele é membro de uma assembléia. Ainda há aquele que falará sobre o presente, podendo citar algum dos outros aspectos temporais, a quem cabe o papel de espectador. Em resumo seria o seguinte:

\section{(presente) ESPECTADOR}

OUVINTE PODE SER

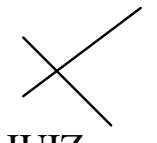

(passado) JUIZ

JUIZ

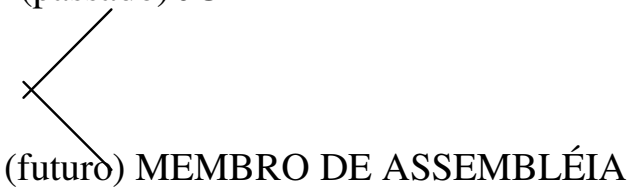

Os gêneros, dentro dessa classificação, seriam:

- Gênero deliberativo (futuro) - aconselha-se ou desaconselha-se;

- Gênero judiciário (passado) - acusa-se e defende-se;

- Gênero demonstrativo ou epidíctico (presente, podendo se utilizar lembranças do passado ou prerrogativas para o futuro) - elogia-se ou censura-se. 
$\mathrm{Na}$ Arte poética, o filósofo de Estagira classifica os gêneros de acordo com o que haveria entre eles de diferenças, ou seja, os diferentes meios, objetos que imitam e as diferentes maneiras de imitá-los. Ele propõe-se a

tratar da produção poética em si mesma e de seus diversos gêneros, dizer qual a função de cada um deles (...) qual o número e natureza de suas diversas partes, e falar igualmente dos demais assuntos relativos a esta produção. (ARISTÓTELES, 1995, p.261)

Os gêneros, segundo Aristóteles, sofriam modificações até atingir sua forma natural (idem, ibidem, p. 267-268). As formas que compunham os gêneros foram hierarquicamente classificadas em sua obra. A fixidez dessa classificação seguia uma linha prescritiva do bem fazer, justificada pela instrumentalização desse conhecimento, já citada anteriormente.

Emil Staiger (apud Todorov e Ducrot, 1972, p. 150), ao modo de Aristóteles, traz o tempo como fator de classificação genérica. Para Staiger a relação temporal dos gêneros acarretaria numa categorização de correspondência. Ele relaciona tempo e gênero como apresento a seguir: o lírico/presente - categorizando a recordação; o épico/passado categorizando a apresentação; o dramático/futuro - categorizando a tensão. Staiger dissociou também tipos de gêneros, dizendo ser próprios do emprego substantivo estes e da adjetivação aqueles.

Historicamente, segue-se, a partir da época clássica, uma tradição literária dos gêneros com a função prescritiva de modelos canônicos para serem reproduzidos, até o momento em que Todorov (1980, p. 43) chama de a crise romântica. Essa crise do início do séc. XIX faz com que esse sistema classificatório de separação dos gêneros venha, aos poucos, sendo reconsiderado, apesar de haver ainda nessa época uma propensão classificatória muito forte. Breure (2001) justifica a tendência da época romântica de se desvencilhar das propostas classificatórias, pela incapacidade que esse sistema teria em dar conta da evolução histórica a que os gêneros são invariavelmente submetidos.

Com os estudos do início do século $\mathrm{XX}$, as discussões sobre gêneros tomam novos direcionamentos, ou sofrem deslocamentos. Com o advento do status de ciência que a lingüística recebe no início desse século e os questionamentos que se seguem a respeito do que vem a ser o objeto dessa nova ciência, buscam-se elementos que caracterizem a língua dentro do que chamo de duas "macro visões": a) uma visão ainda não desvinculada do estruturalismo, no entanto, já questionadora de seus princípios atomísticos e de sua despreocupação quanto ao uso, com Jakobson, Benveniste e Todorov, só para citar alguns; b) 
uma visão construída num diálogo histórico-social, ou seja, constituída na práxis e com tendências marxistas com Bronckart, Bakhtin, Scheneuwly e Dolz.

Trato abaixo de algumas das concepções desses autores citados acima que se relacionam de alguma forma com o desenvolvimento da visão de língua e sua relação com o que poderíamos denominar de concepção de gênero.

JAKOBSON (1987, p.119 e ss), considerando que há uma unidade de língua, mas que, ao mesmo tempo, existem subcódigos, dentro dessa unidade, que se relacionam entre si e exercem funções próprias, propõe que a linguagem seja estudada a partir de suas funções. Ele assume a aproximação entre a poética e a linguiística dizendo que "A Poética trata dos problemas da estrutura verbal (...) [e] Como a Lingüística é a ciência global da estrutura verbal, a Poética pode ser encarada como parte integrante da Lingüística.”. Apresenta-nos, então, esses elementos dentro de uma situação comunicacional, ou de um processo lingüístico, onde a mensagem se projeta de um remetente para um destinatário, através de um contato e de um código próprio e comum aos primeiros. A mensagem requer um contexto para que capacite ambos os indivíduos dessa situação a estabelecer uma comunicação. Para dimensionar o que cada função representa dentro de um quadro de valoração constitutiva, o autor caracteriza as funções de acordo com o relevo que se dá a cada um de seus elementos.

Valendo-se desse esquema, Jakobson aponta seis diferentes funções da linguagem e diz que essas funções podem coexistir dentro de um único texto, dependendo da ênfase que se dá a cada uma delas. As funções são:

1. Função Referencial - centrada no contexto;

2. Função Emotiva - centrada no remetente;

3. Função Conativa - construída a partir da orientação que se queira dar ao destinatário;

4. Função Fática - o discurso focaliza o canal;

5. Função Metalingüística - voltada para a verificação do código

6. Função Poética - a própria mensagem é destacada;

O mérito dessa visão, para o estudo do texto, ainda que estruturante, seria de não mais se tentar acomodá-lo dentro de um único módulo de forma estanque. A prerrogativa de que a heterogeneidade faz parte da constituição de um enunciado provoca uma abertura necessária para as posturas subseqüentes. Um só texto, ou mensagem verbal, pode apresentar mais de uma função e não precisa mais, necessariamente, ser rotulado ou rotulada univocamente. Essa 
simples concepção de fragmentação na própria constituição textual, mesmo que no sentido de justaposição, promove a possibilidade de consideração da busca e não da comprovação.

Com Émile Benveniste temos mais um avanço dentro da estrutura de acontecimento lingüístico: o despontar da consideração da subjetividade e da contextualização imediata desse ato de linguagem.

Benveniste foi aluno de um ex-pupilo de Ferdinand de Saussure e foi também professor de Lingüística no Collège de France. Sua obra Problèmes de linguistique générale é publicada em 1966 e, em 1975, surge o segundo volume, ambos compostos por escritos coletados ao longo de 25 anos. Esses textos traduzem uma evolução das tendências estruturalistas e tratam a linguagem de forma não só lingüística, mas também semiótica e, sobretudo, como veículo de subjetividade (LECHTE, p.56).

Para Benveniste, empregar a forma é diferente de empregar a língua. O emprego da forma, parte necessária para a descrição, é o “conjunto de regras fixando as condições sintáticas nas quais as formas podem ou devem normalmente aparecer (...)" (BENVENISTE, 1989, p. 81), já o emprego da língua é "mecanismo total e constante que, de uma maneira ou de outra, afeta a língua inteira." (op.cit, p.82). Dentro dessa perspectiva, o autor diferencia enunciado de enunciação. O enunciado, segundo ele, corresponderia ao emprego da forma, e a enunciação, o da língua. Para esse autor a "enunciação é este colocar em funcionamento a língua por um ato individual de utilização.” (idem, ibidem).

A despeito de considerar o emprego da língua por um EU que se dirige a um outro, dentro de um AQUI e AGORA, essa iniciativa ainda é uma ação individual. O sujeito toma a língua e a emprega ou a coloca em funcionamento, independentemente do TU do contexto de comunicação. No campo da enunciação o Eu toma a língua por instrumento, como disse, e essa relação pode ser observada nos caracteres lingüísticos que a marcam, apesar de a condição específica da enunciação ser "o ato mesmo de produzir um enunciado, e não o texto do enunciado (...)". Percebo que a conversão de forma em língua é um ato individual dentro desse construto de eu-tu que Benveniste estabelece. O histórico é expresso no sentido de que a enunciação tem necessariamente uma relação com o mundo, de um Aqui e Agora, mas essa relação é de temporalidade porque da "enunciação procede a instauração da categoria do presente, e da categoria do presente nasce a categoria do tempo." (op. Cit. p.. 85)

Exponho acima, de maneira bem, resumida alguns tópicos básicos para 0 entendimento das reflexões que nos interessarão a respeito do trabalho de Benveniste: $1^{\circ} \mathrm{a}$ noção de enunciação, e $2^{\circ}$ a inclusão do sujeito, ou melhor, da subjetividade. Apesar de, didaticamente, apresentar esses tópicos separadamente, entendo que eles estejam imbricados 
pela própria noção que o autor dá a essas duas instâncias teóricas. Em relação à enunciação, posso destacar, como já disse, que há, na verdade, na formulação de enunciação para Benveniste, um ato de apropriação da língua pelo sujeito falante. É um ato em relação à língua e ato não repetível, tornando o campo da enunciação como palco do "novo". Já no que se refere à constituição do eu, mesmo que em função da língua, posso assumir que, para esse autor, a linguagem é pressuposto para a constituição da individualidade e vice e versa, e, já que há o outro para quem se dirige a comunicação, podemos chegar a conclusão também de que, dentro desse construto, não existe linguagem sem comunidade constituída. De alguma forma, mesmo que num sentido restrito, o ato da enunciação constitui o outro.

Essa abertura verificada nos estudos de Benveniste é de extrema importância para os estudos de gênero, primeiro, porque, a partir dessas reflexões, o contexto começa a ser considerado como meio constitutivo dos textos, a língua dentro do histórico (mesmo que imediato). Os textos, por sua vez, circulam numa comunidade de fala própria e são marcados historicamente por caracteres lingüísticos ${ }^{2}$. A subjetividade expressa, nos trabalhos do autor, além de resgatar o sujeito para os estudos lingüísticos, traz a possibilidade desse sujeito ser um alocutário $^{3}$ porque "toda enunciação é explícita ou implicitamente, uma alocução, ela postula um alocutário.” (BENVENISTE, 1989, p.84). Ao contrário da comunicação entre abelhas, por exemplo, o ser humano não se comunica através de estímulo-resposta, logo, para ele "qualquer lingüística que queira fazer justiça à dinâmica da linguagem deve vê-la como uma "instância discursiva" - como discurso, enfim. O discurso é a realização da linguagem" (LECHTE, p. 57), mas, reforçando que esse discurso é contextualizado apenas no imediato.

Mas o que caracterizaria esses acontecimentos enunciativos para que sejam considerados pelos interlocutores como próprios da língua? Bakhtin explica que "cada gênero do discurso em cada campo da comunicação discursiva tem a sua concepção típica de destinatário que o determina como gênero" (BAKHTIN, 2003, p. 301) ou ainda que se "os gêneros do discurso não existissem e nós não o dominássemos, se tivéssemos de criá-los pela primeira vez no processo do discurso, de construir livremente e pela primeira vez cada enunciado, a comunicação discursiva seria quase impossível.” (idem, ibidem, p. 283)

Pensar em como surge um gênero talvez possibilite saber o que um ato de linguagem traz em sua forma que define sua acomodação em determinado campo genérico e não em outro.

\footnotetext{
${ }^{2}$ Para Benveniste (1989, p.82) “A relação do locutor com a língua determina os caracteres lingüísticos da enunciação".

3 "Chama-se, por vezes, alocutário o falante considerado ao mesmo tempo o que recebe enunciados produzidos por um outro locutor e que a ele responde." (Dubois et al., 2001, p.41)
} 
Tratando da origem dos gêneros, não numa perspectiva de resgate histórico, mas de "o que preside, a todo instante, o nascimento de um gênero" (TODOROV, 1980, p. 46), Todorov se questiona a respeito de possíveis formas na linguagem que prenunciem futuros gêneros, que ainda não o são. Mas, o que é um gênero?

Primeiramente o autor tenta chegar a uma possível definição de gênero, pensando, de início, no concreto dos gêneros, ou seja, no discurso ${ }^{4}$. Para ele, o discurso não é composto de frases, mas sim de frases enunciadas. ${ }^{5}$ : "um discurso é sempre e necessariamente um ato de fala" (Idem, Ibidem, p. 47). Apesar de considerar que o discurso está ligado à práxis, afirma que nem todo ato de fala é um gênero (Idem, Ibidem, p. 50) e explica que

uma sociedade escolhe e codifica os atos que correspondem com maior proximidade à sua ideologia; eis porque a existência de certos gêneros numa sociedade, sua ausência numa outra, são reveladoras dessa ideologia e nos permite estabelecê-la com maior ou menor certeza. Não é por acaso que a epopéia é possível numa época, o romance numa outra, o herói individual deste opondo-se ao herói coletivo daquela: cada uma dessas escolhas depende do quadro ideológico no interior do qual ela se dá. (p. 50)

Como vemos na citação acima, Todorov aproxima a ideologia dos gêneros, dando, dessa forma, uma outra conotação para seu estudo. E, se as ideologias estão em permanente contato e transformação, justifica-se porque ele afirma que os gêneros, que estão também em permanente contato, surgem de outros gêneros (op.cit, p.46), ou seja, da mesma forma que as ideologias, transformam-se.

As novas práticas sempre estão relacionadas às praticas anteriores e trazem dessas últimas características comuns. Mesmo que surja um novo gênero devido ao ingresso, na vida social, de uma nova prática, esse movimento não traz o inédito, pois as práticas estão ligadas por reelaborações do velho.

\section{A QUE SE CHEGOU E PARA ONDE SE VAI}

Tratei até agora de uma das instâncias a que me propus. Mesmo que não de forma aprofundada, o histórico foi esboçado a fim de fornecer um panorama das modificações por que passou o trato com a língua/linguagem e conseqüentemente com o gênero. Tratarei

\footnotetext{
${ }^{4}$ Todorov apresenta discurso como sinônimo de texto. (p. 46)

${ }^{5}$ É importante ressaltar, nesse momento, que a enunciação para Todorov fazia parte de um dispositivo contextual ainda bem restrito, mesmo considerando o tempo e o lugar, esses aspectos contextuais ficavam no imediato.
} 
adiante de minha segunda proposta: o desenvolvimento do enfoque que pretendo dar ao termo gênero e o que isso implica no encaminhamento que trago para o processo de ensino/aprendizagem.

Segundo Charaudeau \& Maingueneau (2004, p. 251 ss), desde os anos 90 vem surgindo um novo posicionamento diante do texto. Este vem sendo considerado, dentro dessa nova perspectiva, como lugar das instituições de fala. As mudanças das práticas discursivas que ocasionam os fenômenos genéricos passam a ser foco das principais pesquisas da área. $\mathrm{O}$ receptor passa a ser ponto crucial dentro dessa visão interpretativista. Distanciando-se da concepção de ensino de modelos teóricos da tradição literária e retórica tradicional e da primeira análise de discurso francesa, esses novos estudos trazem duas preocupações básicas: "a reflexão crítica sobre o caráter histórico das tipologias; a descrição das condições de emergência de novas categorias de gêneros e de mutação dos antigos.” (idem, ibidem, p. 252)

Antes de especificar melhor o que vem a ser linguagem para Bronckart (1999, p. 2930) é interessante explorar um importante paralelo significativo que ele expõe em sua obra, a saber, as duas dimensões de estudo da linguagem: a psicológica e a social. Apesar de colocálas de forma independente, ao autor alerta que uma está para a outra como o determinante estaria para o determinado, ou, em outros termos, o constituído. Há, na verdade, uma delimitação e articulação, para fins de análise, do que vem a ser as unidades propriamente sociológicas e as unidades propriamente psicológicas. Nas formações sociais, ou seja, nas unidades representacionais do social, encontraremos a atividade, que é o princípio explicativo das unidades de análise psicológica, na qual observamos as ações. A partir do que exponho sucintamente posso, agora, apresentar um quadro relacional dessas duas instâncias:

\begin{tabular}{|l|l|l|}
\hline DIMENSÕES & RELAÇÕES & FORMAS \\
& ENTRE & REPRESENTACIONAIS \\
& DIMENSÕES & DAS DIMENSÕES \\
\hline PSICOLÓGICA & DETERMINADA & AÇÕES \\
\hline SOCIAL & DETERMINANTE & ATIVIDADE \\
\hline
\end{tabular}

Para Bronckart, o interacionismo sócio-discursivo constitui-se "por considerar as ações humanas em suas dimensões sociais e discursivas constitutivas” (Bronckart, 1999, p. 31). Ele diz ainda que as relações dos indivíduos dessas dimensões, reguladas pelas interações, traz a atividade em consonância com o que Habermas (1987) denomina de agir comunicativo. A linguagem, para Bronckart (1999, p. 34), está primariamente ligada à atividade humana e tem, primordialmente, uma função comunicativa e pragmática. "A 
linguagem propriamente dita teria então emergido, sob o efeito de uma negociação prática (ou incosciente) das pretensões à validade designativa das produções sonoras dos membros de um grupo envolvido em uma mesma atividade.” (BRONCKART, 1999, p.33)

O agir comunicativo é constitutivo na instância social, e conseqüentemente na psicológica, e, por ser construto dessas duas dimensões, torna-se transindividual, "veiculando representações coletivas do meio" (idem, ibidem, p.33).

Para finalizar nossa rápida discussão sobre a linguagem dentro dessa visão sóciointeracionista, trago uma das reflexões de Bronckart, baseada no construto teórico formulado por Vigostski, a respeito da articulação entre linguagem, atividade social e ações. Segundo Bronckart (1990, p. 30), Vigotski considerava a palavra como unidade verbal e não chegou a apontar unidades verbais maiores (gêneros), embora apresentasse certo interesse pela análise das obras literárias. No entanto, segundo ainda Bronckart, à medida que a palavra relacionase com as atividades e as ações, ela é veiculada nessas unidades verbais maiores (gêneros); mesmo Vigostski privilegiando a palavra, ela pode ser considerada como texto e/ou discurso.

Os gêneros compõem-se de atividades de linguagem, que se organizam em discursos ou em textos que, por sua vez, estão em interação com as atividades não verbais. As diversidades de gêneros ocorrem por conta da diversidade dessas interações e, conseqüentemente, da diversidade de significados (BRONCKART, 1999, p. 35).

Os mundos ${ }^{6}$ representados nessas interações, assim como os significados, também estão se transformando permanentemente. O contexto de produção, para Bronckart (1999, p.93 ss), está em dois planos distintos: o primeiro situado num mundo físico, e o segundo relacionado a um mundo social e subjetivo. O primeiro plano é o que tem relação com o espaço e tempo concreto da realização verbal. O segundo é o que se refere

no quadro das atividades de uma formação social e, mais precisamente, num quadro de uma forma de interação comunicativa que implica o mundo social (normas, valores, regras, etc) e o mundo subjetivo (imagem que o agente dá de si ao agir). (idem, ibidem, p. 94)

Em resumo então, temos que:

\section{$1^{\circ}$ PLANO - MUNDO FÍSICO $\rightarrow$ CONCRETUDE DA ATIVIDADE VERBAL; $2^{\circ}$ PLANO - MUNDO SOCIAL $\rightarrow$ LEIS - MUNDO SUBJETIVO $\rightarrow$ AUTO-IMAGEM DO AGENTE}

\footnotetext{
${ }^{6}$ Os mundos, no plural, fazem referência ao que o autor considera como representações coletivas do meio. (Bronckart, 1999, p. 33)
} 
Como, para esse autor, a linguagem é primariamente uma característica da atividade social humana, o gênero funcionaria como formas compartilhadas entre os integrantes da interação verbal, não só como representações sonoras, mas também como representações de entidades de mundo. Concluindo, teríamos que o gênero representaria em sua realização o concreto das atividades verbais, as leis vigentes na sociedade e a própria imagem do agente.

O produto das relações humanas (que é ao mesmo tempo atividade e ação), essas representações, monta formas coletivas. Os textos diversificam-se em gêneros à medida que o processo de semiotização do signo (que é o signo significando) torna-se autônomo. Essa autonomia é relativa visto que os textos, dentro de uma atividade de linguagem própria (gênero), mantêm, entre si, uma relação de troca (Idem, Ibidem, 1999, p. 35). Apesar dessa constatação e de dizer que os gêneros são intuitivamente diferenciáveis, eles nunca poderão ser objeto de uma classificação estável. Para respaldar essa afirmação, expõe-nos três motivos:

O primeiro motivo que corrobora para a impossibilidade de uma sistematização fixa sobre gêneros é, para Bronckart, a infinidade de possibilidades de atividades sociais. O mesmo que Bakhtin reconhece em Estética da Criação Verbal (2003, p.262) quando diz que a pluralidade de atividades de linguagem gera números ilimitados de gêneros. O segundo motivo relaciona-se com os possíveis critérios de uma classificação que estariam intermitentemente em interação, logo, em permanente impossibilidade de delimitação. O único critério objetivável, segundo ele, são as unidades lingüísticas que, por sua vez, não devem ser consideradas como parâmetro de classificação, e esse configuraria o terceiro motivo.

A língua, por sua vez, dispõe recursos morfossintáticos limitados que compõem os segmentos constitutivos de gêneros. E somente esses segmentos podem ser considerados para uma possível elaboração classificatória não de gêneros, mas de tipos de discurso, considerados como "formas específicas de semiotização ou de colocação em discurso"(BRONCKART, 1999, p. 138).

Swales (1990, Apud BALDO, 2006), da maneira de Bronckart, e, como veremos adiante, do próprio Bakhtin, também estabelece uma estreita relação entre gênero e utilização social. Para esse autor, gênero é uma classe de eventos comunicativos. Os objetivos de comunicação do sujeito falante faz com que se configurem os gêneros que, por sua vez, estabelecem instâncias variadas em protótipos. Swales estabelece que 
um gênero engloba uma classe de eventos comunicativos, cujos membros compartilham algum conjunto de objetivos comunicativos. Esses objetivos são reconhecidos pelos membros peritos da comunidade discursiva de origem, e dessa forma constituem a razão para o gênero. Essa razão formata a estrutura esquemática do discurso e influencia e delimita a escolha de conteúdo e estilo (1992, p. 58 Apud BALDO, 2006)

Swales destaca ainda em seus estudos a questão da legitimidade, ou não, do gênero, em uma dada esfera da atividade humana. Essa preocupação não é encontrada nas reflexões de Bakhtin talvez porque a legitimação dos discursos, para ele, se dê no corpo social de forma geral e não de maneira específica. O signo verbal, para Bakhtin, está em permanente reelaboração devido a sua inerência ideológica. A interação verbal entre os interlocutores no contexto sócio-histórico promove a dialogicidade entre ideologias do cotidiano e as ideologias que constituem o corpo social mais abrangente, causando trocas também nesse âmbito. A dialogicidade portanto encontra-se, no mínimo, em quatro grandes campos que se inter-relacionam. São eles:

1. o das relações imediatas entre sujeitos num momento pontual de interação e, por isso, marcado pela práxis;

2. o das ideologias que se dão a nível micro (do cotidiano) e macro (da superestrutura);

3. o das significações que fazem deslizar significados pelos contatos dos signos, permitidos pela língua; e

4. o da troca dialógica entre gêneros.

Nesse último campo dialógico é que vou me ater mais precisamente logo abaixo.

Não podemos concordar com Todorov quando ele diz ser Bakhtin o "pai da pragmática" (1991, p. 42 Apud SILVEIRA, 2005 , p. 58). Minha posição se deve a, pelo menos, dois motivos: primeiro porque a enunciação para Bakhtin é permeada também pelo contexto social mais amplo e, segundo, pela não obrigatoriedade da realização oral, imediata, para que haja dialogicidade, porque

Um traço essencial (constitutivo) do enunciado é o seu direcionamento a alguém, o seu endereçamento. À diferença das unidades significativas da língua - palavras e orações -, que são impessoais, de ninguém e a ninguém estão endereçadas, o enunciado tem autor (e, respectivamente, expressão, do que já falamos) e destinatário. Esse destinatário pode ser um participanteinterlocutor direto do diálogo cotidiano, pode ser uma coletividade diferenciada de especialistas de algum campo especial da comunicação cultural, pode ser um público mais ou menos diferenciado, um povo, os 
contemporâneos, os correligionários, os adversários e inimigos, o subordinado, o chefe, um inferior, um superior, uma pessoa íntima, um estranho, etc; ele também pode ser um outro totalmente indefinido, não concretizado (em toda sorte de enunciados monológicos de tipo emocional).” (Itálico do autor, negrito meu, BAKHTIN, 2003, p. 301)

Quando Bakhtin introduz, em seus estudos, a noção de Compreensão Responsiva Ativa, considero que traz uma nova dimensão para os estudos lingüísticos. Essa compreensão - relativa a resposta que o leitor/ouvinte produz ao ler/ouvir um enunciado - põe em relevo também a não realização verbal oral do pensamento responsivo ativo. E se para ele a "atividade mental" ou pensamento é condicionada/o pela linguagem e pela ideologia conseqüentemente (BAKHTIN, 2004, p.16), logo o que poderia ser chamado de pragmaticismo não se justificaria. Lembremos que a Compreensão Responsiva Ativa não é condicionada somente pela realização verbal oralizada e que as ideologias, via contexto mediato, estão em permanente troca com a linguagem.

O cotidiano constrói e reconstrói as ideologias que, por sua vez, retornam ao cotidiano por meio de (re)significação. As realizações da linguagem perpassada pelas ideologias do cotidiano e das ideologias não tão pontuais formam ou compõem atividades langagières, formam gêneros.

Gênero, para Bakhtin, está impregnado de ideologia, até porque a própria palavra é ideológica (2004, p. 16). Os gêneros que estão em contato mais direto com as ideologias ${ }^{7}$ do cotidiano são os primários. Os gêneros secundários são reelaborações daqueles, ou seja, são práticas mais complexas "com" a linguagem.

Em uma dada ocorrência lingüística o falante/ouvinte produz uma estrutura comunicativa que se configurará em formas-padrão relativamente estáveis de um enunciado, pois são formas marcadas a partir de contextos sociais e históricos também relativamente estáveis. Mesmo que tais formas estejam sujeitas a alterações em sua estrutura, dependendo do contexto de produção e dos falantes/ouvintes que as produzem, há um pré-construto ${ }^{8}$ que atribui sentido a determinado discurso em determinado momento dado. Logo, conclui-se que são muitas e variadas as formas dos gêneros do discurso. Dada essa infinita possibilidade de realizações, Bakhtin divide os gêneros em dois grandes grupos: os primários e os secundários.

\footnotetext{
${ }^{7}$ Bakhtin reformula a relação entre infra-estrutura e superestrutura proposta na teoria marxista que, segundo ele, nessa visão, possuía uma relação direta, sem permeações. Outra questão reformulada por Bakhtin é a acomodação da ideologia ou na consciência do indivíduo ou num conjunto "transcendental" na teoria marxista que, em Bakhtin, assume uma perspectiva dialética de constituição. (MIOTELLO, 2005, p.167-168)

8 "O pré-construído pode ser entendido como a marca, no enunciado, de um discurso anterior; portanto, ele se opõe àquilo que é construído no momento da enunciação. Um sentimento de evidência se associa ao préconstruído, porque ele foi ‘já dito’ (...)” (CHARAUDEAU e MAINGUENEAU, 2004, p. 401)
} 
A diferença entre os gêneros primários e secundários para Bakhtin não é meramente funcional. O gênero secundário é realizado de forma predominantemente escrita e se caracteriza por ser mais complexo, organizado e desenvolvido que o primeiro. Este último, por sua vez, é realizado em condições contextuais imediatas e pode, num processo de transformação, tornar-se secundário (2003, p. 263).

No conjunto que forma os gêneros primários estão contidas as realizações com a linguagem do cotidiano, mais informal e imediata; já no dos elaborados estão contidas as atividades mais formais de linguagem. Realizações e Atividades estão para o tipo primário e o tipo reelaborado, da mesma forma que estão para a infomalidade e a formalidade (não no sentido de modelo, mas sim de pré-construto já definido).

Essas duas instâncias refletem as mudanças que transcorrem na vida social e relacionam a história da sociedade com a da linguagem. Considerando que "a própria escolha de uma determinada forma gramatical pelo falante é um ato estilísitco" (BAKHTIN, 2003, p.269), podemos assumir que a mudança, seja social ou langagière, está intimamente ligada com a questão do sujeito, porque em

\footnotetext{
cada campo existem e são empregados gêneros que correspondem às condições específicas de dado campo; é a esses gêneros que correspondem determinados estilos. Uma determinada função (científica, técnica, publicística, oficial, cotidiana) e determinadas condições de comunicação discursiva, específicas de cada campo, geram determinados gêneros, isto é, determinados tipos de enunciados estilísticos, temáticos e composicionais relativamente estáveis. (Idem, Ibidem, p. 266)
}

Como vimos na citação logo acima, os enunciados variam de acordo com as esferas sociais de comunicação. Baseados nessa afirmação, Schneuwly e Dolz (2004, p.60 -61) dividem os gêneros em agrupamentos de usos. Esses agrupamentos foram formados de acordo com os domínios sociais de comunicação e apresentam aspectos tipológicos diferenciados. Os aspectos são:
a) O narrar;
b) O relatar;
c) $\mathrm{O}$ argumentar;
d) $\mathrm{O}$ expor;
e) A descrição de ações. 
Cada um desses aspectos traz capacidades de linguagem dominantes, relativas a cada ação. $\mathrm{O}$ ato de argumentar, por exemplo, denota capacidade de sustentação, refutação e negociação de tomadas de posição. É dentro de uma classificação de capacidades do ato que assumo o que significará gênero para as atividades que adiante serão propostas.

\section{UMA PROPOSTA}

Como expus no início deste artigo, dizer que se trabalha com gêneros em sala de aula não basta. É necessário que se conceitue esse termo porque, dependendo da concepção que temos dele, as práticas serão diversas.

Retomei, inicialmente, conceitualizações de modelos clássicos e estipulei duas grandes visões de gênero. A primeira, ainda com resquícios estruturalistas, concebe gênero como atividade meramente funcional. O uso, nessa perspectiva, pode até ser considerado, mas dentro de uma visão micro estrutural, ainda muito restrita. A segunda visão constitui-se na práxis e no contexto mediato do materialismo histórico, condições que permitem aos gêneros reelaborações permanentes e constituição flexível e estilística, revelando a autonomia relativa do sujeito (ZOZZOLI, 1999 e 2002).

Com Bakhtin (2003, 2004), Bronckart (1999), Swales (1990), Scheneuwly e Dolz (2004), encontramos uma possível realização de um trabalho com gêneros que avance no intuito de alcançar propósitos educacionais de criticidade do sujeito, de reflexão e compreensão do mundo. Sabendo que

Até mesmo no bate-papo mais descontraído e livre nós moldamos o nosso discurso por determinadas formas de gênero, às vezes padronizadas e estereotipadas, às vezes mais flexíveis, plásticas e criativas (a comunicação cotidiana também dispõe de gêneros criativos). (BAKHTIN,2004, p. 282),

propomos que se aproveite essa profusão de realizações várias, para, num trabalho planejado teórico-metodologicamente, promova-se a elaboração de atividades includentes dos quatro campos que discriminamos acima de efetivação da dialogicidade (campo da interação face a face, das ideologias, das significações, dos gêneros).

Uma atividade que poderia se configurar em trabalhos com gêneros, nesse sentido que propomos, seria o exercício de transformação de tipos primários em tipos reelaborados pelos alunos. Visto que Bakhtin (2003, p. 268) diz: a passagem do estilo de um gênero para outro não só modifica o som do estilo nas condições do gênero que não lhe é próprio como destrói 
ou renova tal gênero, logo, trabalhar essa transformação de gêneros seria constituir uma prática social, num ambiente também social e, por conseguinte, passível de (re)construções ideológicas-significativas.

Como mote para estudo científico, ambas as modalidades, segundo Bakhtin devem ser estudadas. Para esse autor

A diferença entre os gêneros primário e secundário (ideológicos) é extremamente grande e essencial, e é por isso mesmo que a natureza do enunciado deve ser descoberta e definida por meio da análise de ambas as modalidades; apenas sob essa condição a definição pode vir a ser adequada à natureza complexa e profunda do enunciado (e abranger as suas facetas mais importantes); a orientação unilateral centrada nos gêneros primários redunda fatalmente na vulgarização de todo o problema (o behaviorismo lingüístico é o grau extremado de tal vulgarização). A própria relação mútua dos gêneros primários e secundários e o processo de formação histórica dos últimos lançam luz sobre a natureza do enunciado (e antes de tudo sobre o complexo problema da relação de reciprocidade entre linguagem e ideologia)." (grifo meu, 2003, p. 264)

A relação entre linguagem e ideologia é também um movimento de ida e vinda, ou seja, de troca permanente. Schneuwly e Dolz apresentam, como já disse acima, um quadro com agrupamentos de gêneros. Se, primeiramente apontei que um trabalho possível seria a reelaboração de gêneros primários, um segundo passo seria eleger um dos aspectos tipológicos, apresentados por esses dois autores, para um aprofundamento necessário. Depois dessa escolha, montar uma gradação, em nível de dificuldade, levando em conta a reelaboração e apenas um dos aspectos tipológicos, seria um terceiro passo. A opção por determinado aspecto tipológico poderia ocorrer a partir do objetivo que se queira alcançar.

Levando em conta que

o estudo da natureza do enunciado e da diversidade de formas de gênero dos enunciados nos diversos campos da atividade humana é de enorme importância para quase todos os campos da lingüística e da filologia (...) Achamos que em qualquer corrente especial de estudo faz-se necessária uma noção precisa da natureza do enunciado em geral e das particularidades dos diversos tipos de enunciados (primários e secundários), isto é, dos diversos gêneros do discurso. (BAKHTIN, 2003, p. 264)

Os resultados de análise desse possível trabalho poderiam configurar-se em propostas a serem consideradas em práticas futuras. Não no sentido de serem re-aplicáveis, visto que o histórico, a linguagem e as ideologias estão em permanente mudança, outrossim no sentido de serem revisitadas e ressignificadas. 


\section{REFERÊNCIAS}

BAKHTIN, Mikhail (VOLOCHINOV, V.N.). Marxismo e filosofia da linguagem. 11. ed. São Paulo: Hucitec, 2004.

BAKHTIN, Mikhail Estética da Criação Verbal. Tradução de Paulo Bezerra. São Paulo: Martins Fontes, 2003.

BALDO, Alessandra. Gêneros Discursivos ou tipologias textuais? http://64.233.187.104/search?q=cache:cwi3ZUzNvK8J:paginas.terra.com.br/educacao/revel/e dicoes/num_2/g\%25EAneros\%2520discursivos\%2520ou\%2520tipologias\%2520textuais.pdf+ $\mathrm{g} \% \mathrm{C} 3 \%$ AAneros+textuais+e+discursivos $\& \mathrm{hl}=\mathrm{pt}-\mathrm{BR} \& \mathrm{ct}=\mathrm{clnk} \& \mathrm{~cd}=2$ Consultado em junho de 2006.

BENVENISTE, Emile. Problemas de Lingüística Geral II. Tradução: Eduardo Guimarães. Campinas: Pontes, 1989.

BREURE, L. Development of the genre concept. Disponível em www.cs.uu.nl/people/leen/GenreDev/ GenreDevelopment.htm. Consultado em maio de 2005

BRONCKART, Jean-Paul. Atividade de Linguagem, Textos e Discursos. Por um interacionismo sóciodiscursivo. Tradução: Anna Rachel Machado e Péricles Cunha. São Paulo: EDUC, 1999.

CharaUdeAU, Patrick; MAINGUENEAU, Dominique. Dicionário de Análise do Discurso. Tradução: Fabiana Komesu. São Paulo: Contexto, 2004.

DUBOIS, Jean. ET ALL. Dicionário de Lingüística. Ed. 8 São Paulo: Cultrix, 2001.

FARIA, Maria do Carmo Bettencourt de. Aristóteles: a plenitude como horizonte do ser. São Paulo: Moderna, 1994. (Coleção Logos)

JAKOBSON, Roman. Lingüística e Comunicação. Tradução: Izidoro Blikstein e José Paulo Paes. São Paulo: Cultrix, 1987.

LECHTE, John. 50 Pensadores Contemporâneos Essenciais. Do Estruturalismo à PósModernidade. Tradução de Fábio Fernandes. 3. ed. Rio de Janeiro: Difel, 2003.

MIOTELLO, Valdemir. Ideologia. In: BRAIT, Beth. (org) Bakhtin. Conceitos Chaves. São Paulo: Contexto, 2005.

SAUSSURE, Ferdinand de. Curso de Lingüística Geral. 25.ed. Tradução: Antônio Chelini, José Paulo Paes e Izidoro Blikstein. São Paulo: Cultrix, 2003.

SCHNEUWLY, Bernard; DOLZ, Joaquim. Gêneros Orais e Escritos na Escola. Tradução e organização: Roxane Rojo e Glaís Sales Cordeiro. Campinas, SP: Mercado de letras, 2004.

SILVEIRA, Maria Inez Matoso. Análise de Gêneros Textual. Concepção Sócio-Retórica. Maceió: Edufal, 2005. 
TODOROV, Tzvetan. Os gêneros do discurso. Tradução: Elisa Angotti Kossovitch. São Paulo: Martins Fontes. 1980. 